\section{Low Night Temperature Increases Ovary Size in Sweet Pepper Cultivars}

\author{
Nicacio Cruz-Huerta ${ }^{1}$, Jeffrey G. Williamson, and Rebecca L. Darnell ${ }^{2}$ \\ Horticultural Sciences Department, University of Florida, P.O. Box 110690, \\ Gainesville, FL 32611
}

Additional index words. Capsicum annuum, fruit deformation, ovary swelling, ovary wall, placenta

\begin{abstract}
Cool night temperatures have been reported to induce ovary swelling and consequent fruit deformation in bell pepper (Capsicum annuum L.), resulting in unmarketable fruit. This response is a serious limitation to the success of winter production systems for bell pepper. Limited work has been done with other types of sweet pepper, so it is unknown how universal this response is. Furthermore, most prior work has examined effects on ovary diameter only, and there is limited characterization of other ovary traits in response to cool night temperature. The objectives of the present study were to determine the effects of low night temperature on ovary characteristics in different sweet pepper cultivars and to determine the parts of the ovary that are most affected by these factors. Three types of sweet pepper (bell, long-fruited, and cherry) were exposed to $22 / 20$ or $22 / 12{ }^{\circ} \mathrm{C}$ day:night temperatures and flowers at anthesis were continuously harvested throughout the experiments. Ovary fresh weight (FW), diameter, and length across all types (and cultivars within type) were greater under $22 / 12{ }^{\circ} \mathrm{C}$ compared with $22 / 20^{\circ} \mathrm{C}$. The increase in ovary $\mathrm{FW}$ was the result of increases in both ovary wall and placenta $\mathrm{FW}$. In general, all cultivars exhibited increases in ovary size under $12^{\circ} \mathrm{C}$ compared with $20^{\circ} \mathrm{C}$ night temperature. Differences in ovary $\mathrm{FW}$ resulting from night temperature became more pronounced with time. These results indicate that low night temperature effects on ovary swelling may be a universal response among sweet pepper types. Three to 4 weeks are required for maximum swelling response, suggesting that flower buds must be exposed to low night temperatures within the first week after flower bud initiation, because previous work found that flower bud initiation in bell pepper takes $\approx 4$ weeks. However, the duration of low night temperatures necessary for this response remains unknown.
\end{abstract}

Peppers (Capsicum annuum L.) are an important horticultural crop belonging to the Solanaceae family and are grown in both tropical and temperate climates (Eshbaugh, 1993). Hot peppers are consumed fresh, dried, or processed, mostly as a spice or as a source of food colorants or capsaicin. Sweet peppers are an important green vegetable crop worldwide, especially in temperate regions (Bosland, 1996; Eshbaugh, 1993). There is large variability in sweet pepper fruit size and shape, ranging from cherry (spherical, $\approx 2.5$ to $3.5 \mathrm{~cm}$ in diameter), to long-fruited (banana or cubanelle), to bell (blocky) peppers, which are the most important from an economic standpoint (Bosland, 1996). In the United States, per-capita consumption of bell peppers increased from $1 \mathrm{~kg}$ in 1970 to $\approx 3$ $\mathrm{kg}$ in the late 1990s and has remained steady during the last 10 years (USDA Economic Research Service, 2008).

Fruit shape, size, and uniformity are important quality components in sweet peppers. Final fruit shape is the result of genetic and environmental factors (Perin et al., 2002), and it is defined in the early stages of fruit development (Munting, 1974). In bell, spherical,

Received for publication 9 Nov. 2010. Accepted for publication 17 Dec. 2010.

${ }^{1}$ Current address: Colegio de Postgraduados, Montecillo, Edo. de México, C.P. 56230 México.

${ }^{2}$ To whom reprint requests should be addressed; e-mail rld@ufl.edu. and ovoid fruited pepper varieties, shape definition takes place before pollination occurs (Aloni et al., 1999; Munting, 1974). However, in long-fruited varieties, fruit shape is defined during both the preanthesis and postanthesis stages (Munting, 1974). In all genotypes, pollination and fertilization are key factors in attaining the ideal size, shape, and uniformity (Mercado et al., 1997b).

Sweet peppers, like with other fresh fruits and vegetables, are a commodity in demand all year. To fill that market need, sweet pepper production during the winter has been developed in areas with warm or mild winters or even in cold winters under greenhouse conditions. However, when grown in mild winter areas that are subject to cool nights, or when grown under greenhouse conditions in cold winters, bell peppers can develop up to $60 \%$ flattened and deformed fruits and thus are unmarketable (Ali and Kelly, 1993; Aloni et al., 1999).

Several reports have previously addressed the effect of low night temperature (LNT) on flower and fruit development and malformation in sweet pepper. However, they have mainly focused on pollen quality (Mercado et al., 1997a; Pressman et al., 1998a; Shaked et al., 2004), pollination (Mercado et al., 1997b; Pressman et al., 1998a), number of seeds (Kato, 1989), and fruit quality (Kato, 1989; Pressman et al., 2006). Only a few studies have focused on flower and ovary malformation and swelling, and these studies have been limited to effects in bell pepper (Aloni et al., 1999; Pressman et al., 1998b). Flower deformations resulting from LNT include abnormal and curled petals that do not fully expand, shorter stamens with low pollen content and low germination rates, and larger ovaries with shorter styles compared with flowers developed under intermediate or high temperatures (Aloni et al., 1999; Mercado et al., 1997a; Polowick and Sawhney, 1985; Pressman et al., 1998a; Shaked et al., 2004). The ovary enlargement observed under cool temperatures is referred to as ovary swelling (Aloni et al., 1999; Pressman et al., 1998b). Ovaries developed under LNT are impaired in fruit development, even when pollinated with viable pollen, and result in smaller, irregularly shaped fruit compared with fruit developed under higher night temperatures (Pressman et al., 1998a).

Although the effects of LNT on ovary swelling in bell peppers are documented, LNT effects in other types of sweet peppers are unknown. Low night temperature may affect ovary shape differently depending on the type of sweet pepper. Therefore, the hypothesis tested in this work is that LNT increases ovary size and causes ovary swelling in a range of pepper types differing in final fruit shape and size. The objectives were to 1 ) determine the effects of LNT on ovary size in six cultivars and three types of sweet pepper; and 2) determine the parts of the ovary that are most affected by LNT.

\section{Materials and Methods}

Plant material and growing conditions. Seedlings of six (Expt. 1) or four (Expt. 2) sweet pepper varieties were germinated using a mix of commercial potting media (SunGro Metro-Mix Ag-Lite Mix, Bellevue WA) and perlite (4:1 $\mathrm{v}: \mathrm{v})$ in 40 -cell flats $\left(60 \mathrm{~cm}^{3}\right.$ each cell $)$ in $1.4-\mathrm{m}^{2}$ growth chambers (E15 Conviron, Winnipeg, Canada). Chamber temperature was set to $22 / 20{ }^{\circ} \mathrm{C}$ (day/night) and photosynthetic photon flux was maintained between 450 and 500 $\mu \mathrm{mol} \cdot \mathrm{m}^{-2} \cdot \mathrm{s}^{-1}$ above the canopy with a $14-\mathrm{h}$ photoperiod. Light was provided by fluorescent and incandescent lights.

Seedlings at approximately the sixth-leaf stage (54 d after sowing) were transplanted into $1.5-\mathrm{L}$ containers using the same media mix. Plants were continuously pruned once branching began. At the first branching point, two shoots were allowed to grow, forming the main stem sympodial unit, consisting of the two sympodial (lateral) shoots, the flower in the vertex of the shoots (i.e., the terminal flower from the preceding shoot), and the single leaf at the distal end of each sympodial shoot (i.e., two leaves as a result of the presence of two sympodial shoots) (Fig. 1). For the subsequent sympodial units, the strongest shoot was allowed to grow (contributing to the main axis of the plant) and the other shoot was allowed to develop one sympodial unit (forming a lateral branch) before pruning. Sympodial units formed on the main stem sympodial unit were numbered SU1 (sympodial unit 1), which in turn bore SU2. Subsequent sympodial units were numbered 3, 4, ..., n (see Elitzur et al., 2009). For the purpose of this study, nodes above the first 


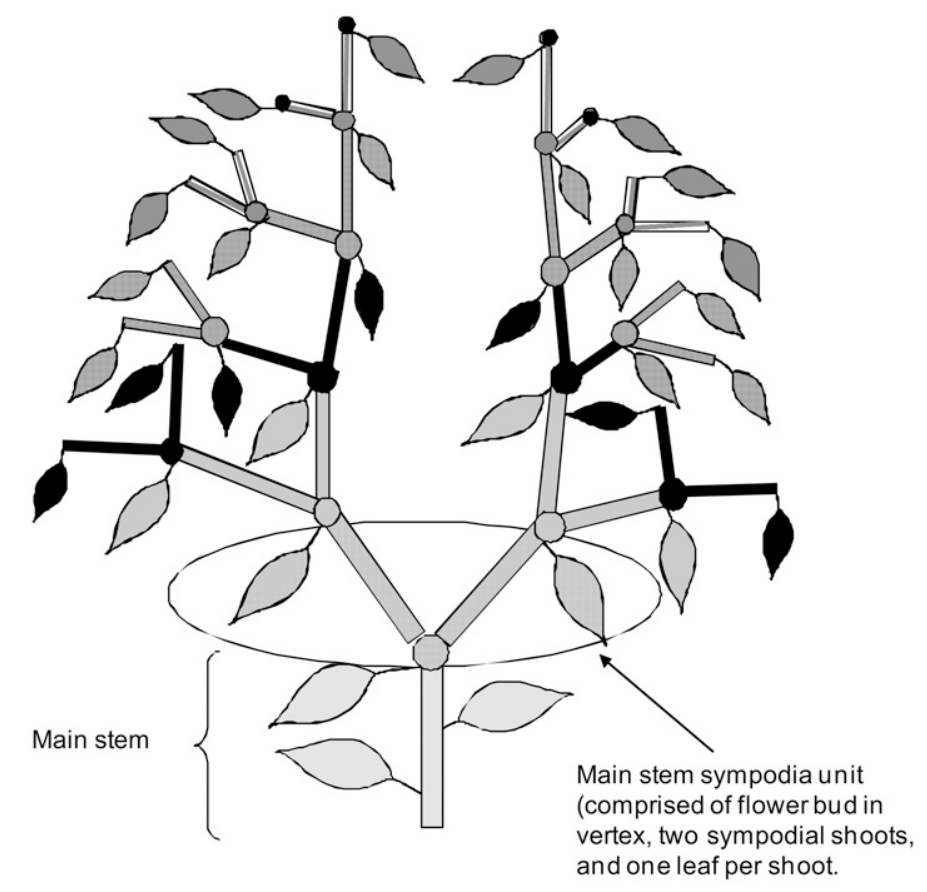

\begin{tabular}{|l|}
\hline$\square$ Main stem \\
$\square$ Main stem sympodial unit(SU) \\
$\square$ sU 1 \\
$\square$ SU 2 \\
$\square$ SU 3 \\
$\square$ su 4
\end{tabular}

Fig. 1. Schematic drawing of the branching pattern and sympodial units of pepper plants used in Expts. 1 and 2. The main stem ended in a single flower and the axillary buds in the two or three preceding leaves developed the leaves in the main stem sympodial unit (SU). Starting in SU1, the strongest shoot was allowed to grow and the second shoot was limited to development of one sympodial unit (one flower and two leaves) by pruning. Flowers from the main stem and first SU were removed before treatment started.

branching point were also numbered according to their sympodial unit to describe each flower's position, i.e., node 1 (corresponding to SU1), node 2 , node 3 , etc. Flowers from the main stem and node 1 (i.e., SU1) were removed at the flower bud stage.

Expt. 1. This experiment was designed to determine the response of six cultivars of sweet pepper to low night temperature. Four blocky bell-type pepper cultivars (Ariane, Aristotle, Brigadier, Legionnaire), one long-fruited cultivar (Banana Supreme, length:diameter ratio $\approx 4$ ), and one cherry-type cultivar (Red Cherry Sweet, rounded, 2.5 to $3.7 \mathrm{~cm}$ diameter) were exposed to day temperatures of $22{ }^{\circ} \mathrm{C}$ and one of two night temperatures: $20^{\circ}$ [high night temperature (HNT)] or $12{ }^{\circ} \mathrm{C}$ (LNT). Temperatures were maintained by measuring leaf tissue temperatures at several points in the chambers with thermocouples connected to data loggers and adjusting air temperature settings to maintain average tissue temperature of $22{ }^{\circ} \mathrm{C}$ during the day. Several cultivars of bell pepper were tested because previous work on ovary swelling as a response to night temperature was done primarily with a single bell pepper cultivar, Mazurka (Aloni et al., 1999; Pressman et al., 1998a, 1998b). The design was completely random with three single plant replications. Plants were fertigated starting at $\approx 6$ weeks after seeding with $20 \mathrm{~N}-6.7 \mathrm{P}-16.7 \mathrm{~K}$ water-soluble fertilizer (Scotts-Sierra Horticultural Products Company, Marysville, $\mathrm{OH}$; www.scottsprohort.com). Application rates were $\approx 1 \mathrm{mg}$ nitrogen $(\mathrm{N})$ per plant per day before transplanting (54 d after sowing) and from 15 to $50 \mathrm{mg} \mathrm{N}$ per plant per day after transplanting, depending on plant age. Starting at 7 weeks after transplanting, plants were fertigated as needed with the following nutrient solution (mM): $3.4 \mathrm{Ca}\left(\mathrm{NO}_{3}\right)_{2}, 1.8 \mathrm{KNO}_{3}, 1.6 \mathrm{KH}_{2} \mathrm{PO}_{4}$, $0.3 \mathrm{KCl}, 2.7 \mathrm{MgSO}_{4}$, and $(\mu \mathrm{M}) 50.2 \mathrm{Fe}-\mathrm{EDTA}$, $3.1 \mathrm{CuSO}_{4}, 14.6 \mathrm{MnSO}_{4}, 64.8 \mathrm{H}_{3} \mathrm{BO}_{3}, 4.6$ $\mathrm{ZnSO}_{4}, 0.6 \mathrm{Na}_{2} \mathrm{MoO}_{4}$ (modified from CruzHuerta et al., 2005; Jovicich et al., 2007). Plants were watered with room temperature water in the morning to increase root-zone temperature in the LNT treatment (Ying et al., 2002) so that day temperature was similar in the root and shoot in both LNT and HNT.

Night temperature treatments began just before anthesis of flowers in node 3 ('Ariane' and 'Aristotle'), 4 ('Brigadier', 'Legionnaire', and 'Banana Supreme'), or 5 ('Red Cherry Sweet'). Once treatments started, all the flowers at anthesis were continuously harvested during a 39-d period in 'Brigadier', 'Legionnaire', 'Banana Supreme', and 'Red Cherry Sweet' and a 64-d period in 'Ariane' and 'Aristotle'. The flower harvest period was prolonged in these latter two cultivars as a result of a delay in their growth and development after transplanting. Plants did not bear any fruit before or during the experiment. Flower harvests occurred every 2 to $3 \mathrm{~d}$ during the first $50 \mathrm{~d}$ and everyday during the last $13 \mathrm{~d}$. A minimum of 66 flowers per night temperature and cultivar combination were harvested. The flower position in the plant (i.e., node number above first terminal flower and whether it was in the main axis or in a lateral branch) was recorded. Ovary $\mathrm{FW}$, diameter, and length were recorded.

Expt. 2. Based on the results from the first experiment, four cultivars, Ariane, Legionnaire, Banana Supreme, and Red Cherry Sweet, were selected for Expt. 2. The criteria used to select the cultivars were 1) contrasting responses to LNT in bell peppers ('Ariane', in which ovary FW was unaffected by night temperature, and 'Legionnaire', in which ovary FW was significantly increased under LNT); and 2) contrasting fruit shape and size (bell, long-fruited, and cherry types). Two night temperatures regimes, high $\left(\mathrm{HNT}, 20^{\circ} \mathrm{C}\right)$ and low $\left(\mathrm{LNT}, 12^{\circ} \mathrm{C}\right)$, were studied. Plants of each cultivar were randomly assigned to temperature treatments in a randomized complete block design six replications. Starting $\approx 4$ weeks after seeding, plants were fertigated as needed with the nutrient solution indicated in Expt. 1.

Treatments began just before anthesis of flowers on the second sympodial unit (node 2). Flowers were harvested everyday at anthesis for up to $45 \mathrm{~d}$, from the second to the seventh nodes above the first terminal flower. Like in Expt. 1, plants did not bear any fruit. The position of all harvested flowers in the plant was recorded. Ovary FW, diameter, and length were recorded. Ovaries were dissected and ovary wall and placental FW was determined.

Statistical analysis. Data from Expt. 1 were grouped into five harvest intervals (harvest intervals I to V). For 'Brigadier', 'Legionnaire', 'Banana Supreme', and 'Red Cherry Sweet', harvest intervals were $8 \mathrm{~d}$, and for 'Ariane' and 'Aristotle', harvest intervals were $13 \mathrm{~d}$ because development was delayed in these two cultivars. Data were analyzed as a completely randomized design with repeated measures. A mixed model was applied with cultivar, night temperature, and harvest interval as the fixed effects, axis (i.e., main axis or lateral branch) nested within each plant as the repeated-measures subject, and days after anthesis as the covariate.

Data from Expt. 2 were also analyzed as a completely randomized design with repeated measures. A mixed model was used with temperature, cultivar, node number, and axis (main axis, lateral branch) of the harvested flower as the fixed effects and block as the random effect. Temperature and cultivar were handled as the main model effects and node number and axis as submodel effects. The subject for the repeated measures was an individual plant.

Data were analyzed using SAS (SAS Institute Inc., 2008), and mean separation was done using Tukey-Kramer (multiple least squares means) or $t$ test (two means). 


\section{Results}

Expt. 1. Approximately 30 flowers per plant reached anthesis and were harvested during the experiment with no significant difference in flower number among cultivars (data not shown). Low night temperature decreased the number of flowers compared with HNT across all cultivars (27.1 versus 33.2 , respectively; $P \leq 0.01$ ). The decrease in flowers harvested at LNT was correlated with a decrease in node number under LNT compared with HNT (6.8 versus 8.4, respectively; $P \leq 0.01$ ).

The effects of night temperature on ovary FW, diameter, and length varied with cultivar. When comparing the average effect of the night temperature treatment on ovary characteristics during all harvest intervals, significant differences were detected only in 'Aristotle' and 'Legionnaire' (data not shown). However, when only the flowers harvested during the last two harvest intervals of the experiment (harvest intervals IV and V) are considered, significant increases in ovary FW resulting from LNT were found in the bell-type 'Aristotle', 'Brigadier', and 'Legionnaire' and the longfruited type 'Banana Supreme' (Fig. 2). Ovary diameter was significantly greater under LNT only in 'Aristotle' and 'Brigadier', whereas ovary length increased under LNT in 'Brigadier', 'Legionnaire', and 'Banana Supreme'.

In general, differences in ovary FW resulting from night temperature became more pronounced with time depending on cultivar (Fig. $3)$. There was no effect of night temperature during the first 3 weeks of treatment (i.e., harvest intervals I and II for 'Aristotle' and 'Ariane' and I to III for 'Brigadier', 'Legionnaire', 'Banana Supreme', and 'Red Cherry Sweet') in any cultivar. Subsequently, ovary FW of flowers at anthesis in three of four bell pepper varieties ('Aristotle', 'Brigadier', and 'Legionnaire') and in the long-fruited variety ('Banana Supreme') increased under LNT compared with HNT. However, in this experiment, ovary FW of 'Ariane' (bell) and 'Red Cherry Sweet' (cherry) did not significantly increase under LNT compared with HNT. In general, 3 to 4 weeks of LNT were required to significantly increase ovary $\mathrm{FW}$ compared with HNT-treated plants. In four of six cultivars, ovary FW did not change under HNT throughout the harvest intervals.

Expt. 2. Night temperature effects on ovary FW and diameter differed with cultivar. All pepper types grown under LNT produced flowers with greater ovary FW compared with plants grown under HNT. However, the increase in ovary FW under LNT varied among types, ranging from $50 \%$ in 'Banana Supreme' to $76 \%$ in 'Legionnaire' (Fig. 4). When ovaries were separated into ovary wall and placental tissue, increases in ovary wall FW under LNT were observed in all four pepper types with increases ranging from $47 \%$ ('Red Cherry Sweet') to $85 \%$ ('Legionnaire'). Low night temperatures also increased placenta $\mathrm{FW}$ in bell pepper flowers ('Ariane' and 'Legionnaire') and cherry-type ('Red Sweet Cherry'), but not in the long-fruited type 'Banana Supreme'. There were differences in the percent
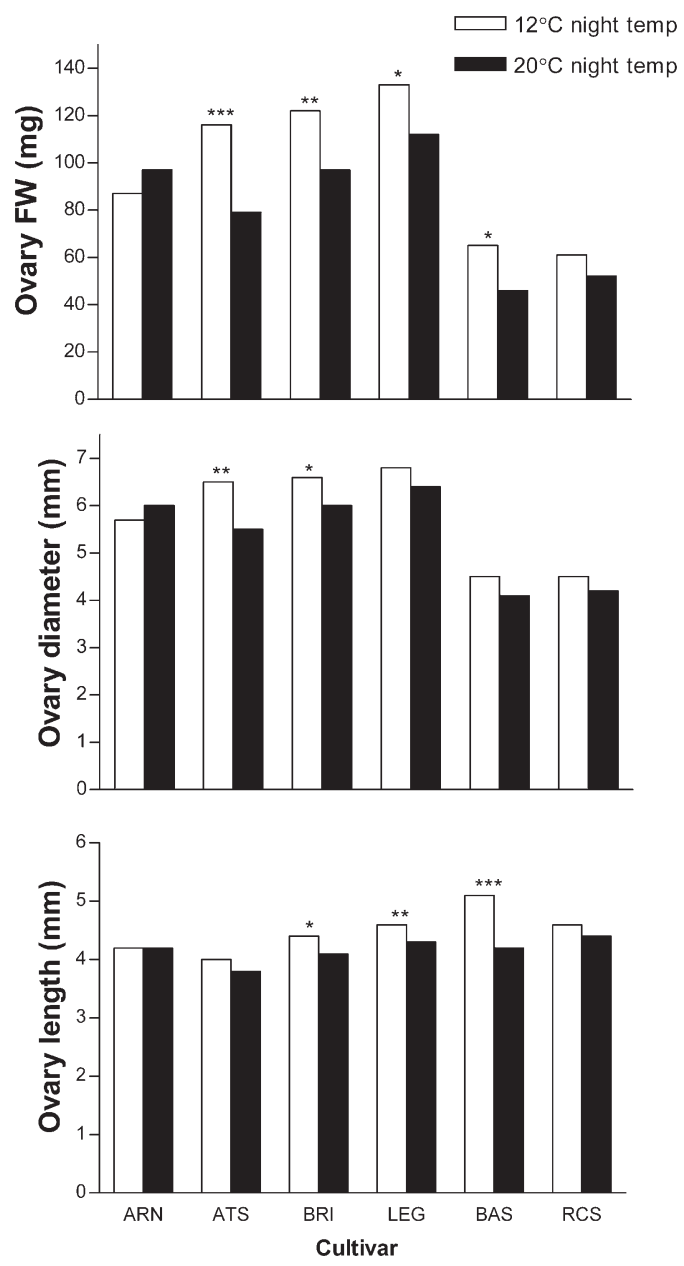

Fig. 2. Interaction of night temperature and cultivar on ovary characteristics of sweet pepper flowers harvested at anthesis during the last two harvest intervals (Expt. 1). Flowers were continuously harvested at anthesis between 40 and $64 \mathrm{~d}$ after treatment began for 'Ariane' (ARN) and 'Aristotle' (AST) and between 25 and 39 d after treatments began for 'Brigadier' (BRI), 'Legionnaire' (LEG), 'Banana Supreme' (BAS) and 'Red Cherry Sweet' (RCS). Means were averaged for each cultivar across the last harvest intervals. $* * *, * * *$ Means within a cultivar were significantly different between the two temperature treatments at $P \leq 0.05,0.01$, or 0.001 , respectively; $\mathrm{n}=75$ to 107 , depending on temperature treatment and cultivar.

of the total ovary FW contributed by the placenta and ovary wall. In 'Ariane' and 'Legionnaire', the ovary wall FW represented $\approx 50 \%$ of the total $\mathrm{FW}$, whereas in 'Banana Supreme' and 'Red Cherry Sweet', the ovary wall represented $\approx 65 \%$ of the total FW. The ovaries from plants grown under LNT also increased in both diameter and length, except for the long-fruited cultivar, which increased only in length.

Ovary FW increased with node number in all cultivars under LNT, whereas under HNT, ovary FW increased with node number only in 'Legionnaire' (Fig. 5). 'Ariane' and 'Legionnaire' (bell type) responded faster to night temperature treatments than 'Banana Supreme' and 'Red Cherry Sweet'. In 'Legionnaire', for example, LNT significantly increased the ovary size compared with HNT starting at node 2, which was harvested $8 \mathrm{~d}$ after the beginning of treatment (DAT). In contrast, in 'Red Cherry Sweet', significant differences between temperature treatments were not found until node 5 (20 DAT). In 'Ariane', differences in ovary FW resulting from night temperature treatments began by node 4 (21 DAT). However, maximum ovary swelling was reached after node 5 for all cultivars (20 DAT in 'Red Cherry Sweet' to 31 DAT in 'Legionnaire').

Although ovary FW increased more than diameter and length at LNT compared with HNT within each cultivar (Fig. 4), both diameter and length responded as quickly as FW to night temperature treatments (data not shown). In fact, in 'Banana Supreme' and 'Red Cherry Sweet', significant differences in length were found earlier (i.e., node 4) than were differences in FW and diameter (i.e., node 6).

\section{Discussion}

Low night temperature increased ovary FW and diameter in three different types of sweet pepper: bell, long-fruited, and cherry. Most of the studies involving LNT effects on ovary and fruit development have been on large-fruited bell pepper and have focused primarily on LNT effects on ovary diameter (Aloni et al., 1999; Bhatt and Srinivasa-Rao, 1993; Polowick and Sawhney, 1985). Limited 

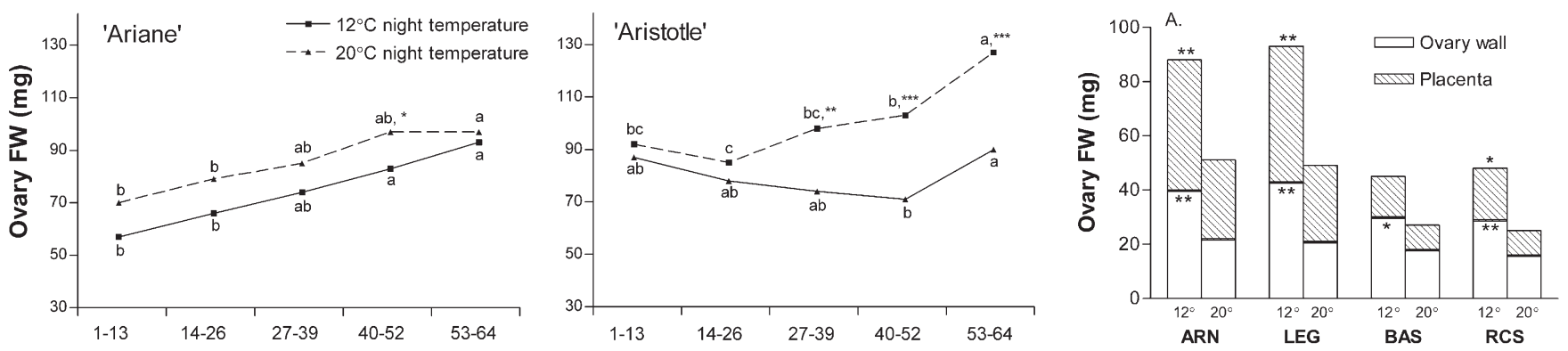

Days after treatment
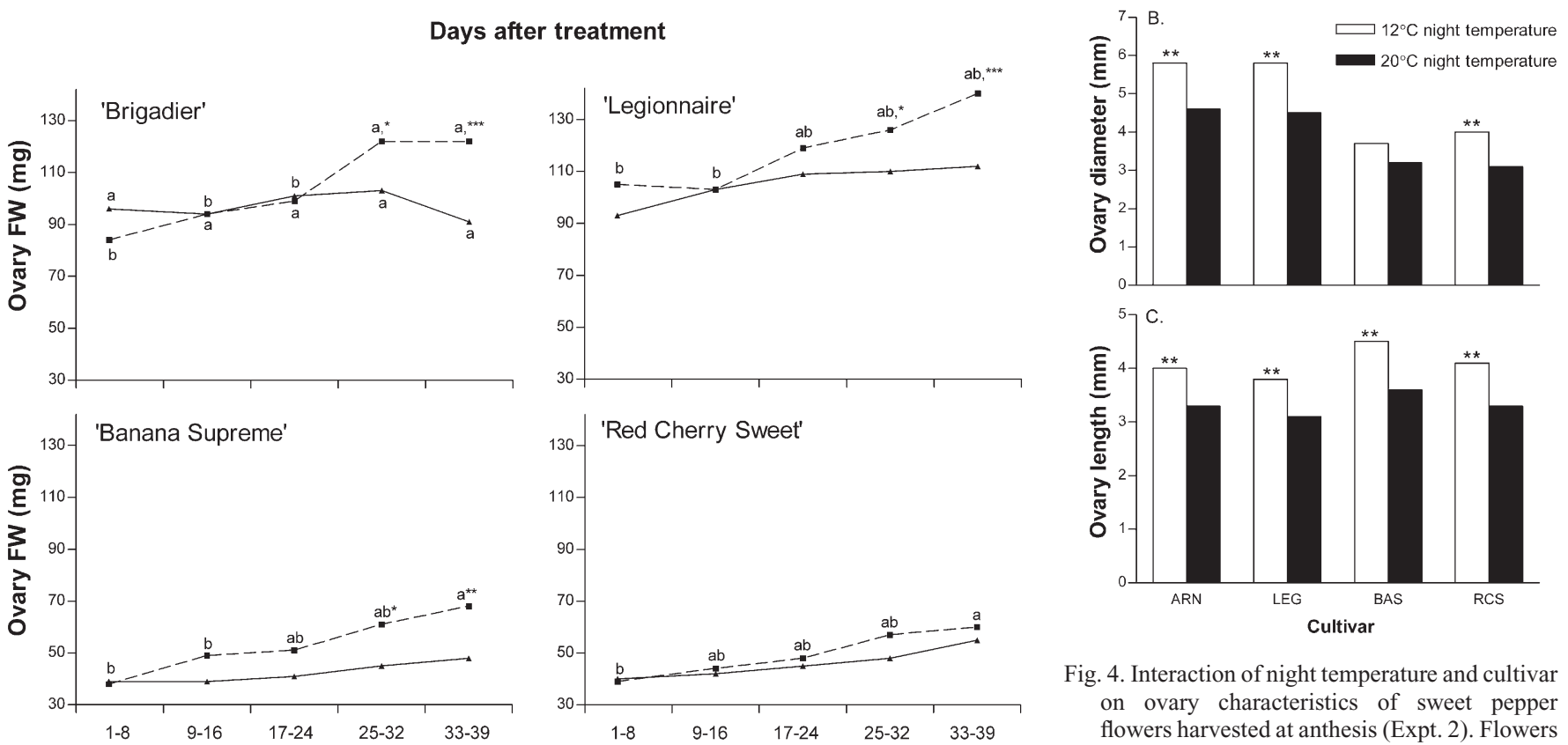

Days after treatment

Fig. 3. Ovary fresh weight of sweet pepper flowers at anthesis developed under $22 / 12{ }^{\circ} \mathrm{C}(--)$ or $22 / 20^{\circ} \mathrm{C}$ $(-\bullet)$ day/night temperatures for discrete harvest intervals (Expt. 1). Harvest intervals were $13 \mathrm{~d}$ for 'Ariane' and 'Aristotle' and $8 \mathrm{~d}$ for 'Brigadier', 'Legionnaire', 'Banana Supreme', and 'Red Cherry Sweet'. Plants did not bear any fruit before or during the experiment. Means with the same letter in the same temperature treatment and cultivar were not significantly different (Tukey-Kramer, $P \leq 0.05$ ). If means within a temperature treatment were not significantly different from each other at any time, mean separation letters were not included. $*, * *, * * *$ Means between temperature treatments within a harvest interval for each cultivar were significantly different at $P \leq 0.05, P \leq 0.01$, and $P \leq 0.001$, respectively. Range of $\mathrm{n}$ values for harvest intervals I, II, III, IV, and V are 7 to 20,11 to 25,12 to 23,12 to 29 , and 14 to 35 , respectively.

work has been done on other sweet pepper types and these studies focused on temperature effects on pollen development and fertility, not on ovary development (Kato, 1989; Mercado et al., 1997b; Shaked et al., 2004). Our results expand beyond the previous work and suggest that LNT effects on ovary swelling may be a generalized response among sweet pepper types. Thus, even in those pepper types in which post-anthesis cell division and elongation influence final fruit shape (i.e., the longfruited 'Banana Supreme') (Munting, 1974), LNT before floral anthesis induced ovary swelling. Our results further indicate that under LNT conditions, the increase in ovary FW is proportionately greater than the increase in ovary diameter or length. Most previous studies have measured night temperature effects on ovary diameter, not FW or length (Aloni et al., 1999; Polowick and Sawhney, 1985). Our results suggest that LNT effects on ovary swelling in peppers, and subsequent effects on fruit malformation, may be better predicted by looking at effects on ovary FW in bell peppers. However, in long-fruited cultivars such as 'Banana Supreme', ovary length may also be a good indicator of ovary swelling, because length increased more rapidly than did FW in response to LNT compared with HNT.

In general, sweet pepper cultivars developing under LNT required from 3 to 4 weeks to develop swollen ovaries. In the main stem of bell pepper, floral initiation occurs between the sixth and the seventh leaf, regardless of temperature (Choi and Gerber, 1992). At day/ night temperatures of $28 / 15{ }^{\circ} \mathrm{C}$, it takes $\approx 4$ weeks from the sixth leaf to anthesis of the first flower (Cruz-Huerta et al., 2005). This suggests that flower buds must be exposed to LNT within the first week after flower bud initiation to develop a large percentage of swollen ovaries. The exception to this was observed in
Fig. 4. Interaction of night temperature and cultivar on ovary characteristics of sweet pepper flowers harvested at anthesis (Expt. 2). Flowers were continuously harvested at anthesis from nodes 5 to 7 for 'Ariane' (ARN), 'Legionnaire' (LEG), 'Banana Supreme' (BAS) and 'Red Cherry Sweet' (RCS). Means were averaged for each cultivar across all nodes harvested. $*, * *$ Mean ovary wall or placental fresh weight within a cultivar were significantly different between the two temperature treatments at $P \leq$ 0.01 and $P \leq 0.001$, respectively; $\mathrm{n}=23$ to 68 , depending on temperature treatment and cultivar.

'Legionnaire' bell pepper in Expt. 2, in which significant increases in ovary size occurred after $\approx 1$ week of LNT compared with HNT. Even so, $\approx 30 \mathrm{~d}$ of LNT were required for maximum increases in ovary size to be manifested in 'Legionnaire'. To our knowledge, this is the first evidence that sweet pepper ovaries are most sensitive to LNT effects (with respect to ovary swelling) during flower bud initiation.

Although a critical period for LNT exposure was revealed in our work (i.e., within the first week after flower bud initiation), the duration of LNT exposure required for development of swollen ovaries was not examined, because plants were exposed to low or high night temperatures continuously throughout the experiments. It is clear, however, that the percentage of flowers that exhibit ovary swelling increases as the duration of the LNT exposure increases. This has been demonstrated previously in bell pepper (Aloni et al., 1999) and reflects the continuous floral initiation nature of pepper.

Previous work on ovary swelling in pepper focused only on the whole ovary. Our 

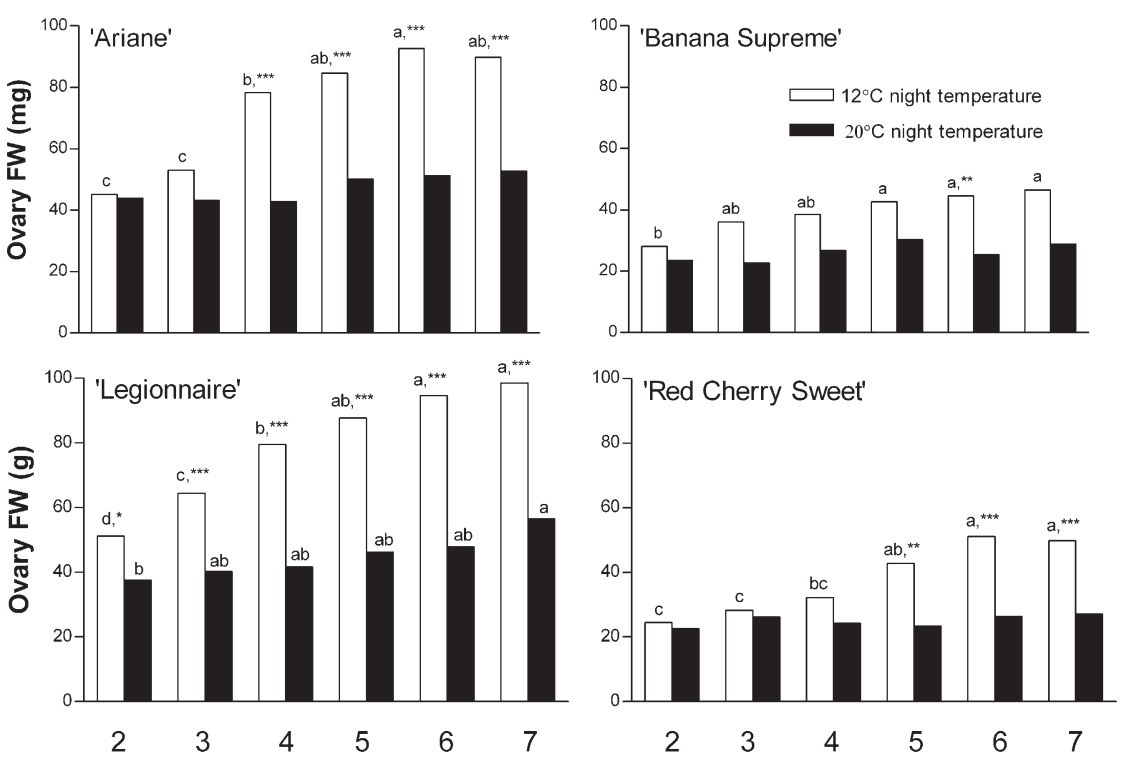

\section{Node above first branching}

Fig. 5. Ovary fresh weight of sweet pepper flowers harvested at anthesis from the second to the seventh nodes above the first flowering node in plants developed under $22 / 12{ }^{\circ} \mathrm{C}(-\bullet-)$ or $22 / 20{ }^{\circ} \mathrm{C}(-\bullet-)$ day/ night temperatures (Expt. 2). Plants did not bear any fruit before or during the experiment. Means with the same letter in the same temperature treatment and cultivar were not significantly different (TukeyKramer, $P \leq 0.05)$. *,**,***Means between temperature treatments within a node number for each cultivar were significantly different at $P \leq 0.05, P \leq 0.01$, and $P \leq 0.001$, respectively. Range of $\mathrm{n}$ values for $22 / 12$ and $22 / 20{ }^{\circ} \mathrm{C}$ temperature treatments were 15 to 23 and 8 to 24 , respectively, excluding 'Banana Supreme' node 2, where $\mathrm{n}=2$.

data show that the ovary wall FW:total ovary FW ratio varied among types of cultivars, averaging $\approx 65 \%$ for the non-bell pepper cultivars (Banana Supreme and Red Cherry Sweet) and $\approx 50 \%$ for the bell pepper cultivars (Ariane and Legionnaire). However, LNT did not change the ratios, indicating that the increase in ovary FW for all but 'Banana Supreme' was the result of proportional increases in ovary wall and placenta, and therefore the ratio of ovary wall:total ovary did not change with night temperature treatments. In 'Banana Supreme', the increase in ovary FW under LNT was mainly the result of increased ovary wall $\mathrm{FW}$; however, the ovary wall FW:total ovary FW ratio did not change, likely as a result of the small increase in placenta FW. It is probable that the factors that induce swelling in both the ovary wall and the placenta are similar. Thus, greater insight into physiological changes that correlate with ovary swelling may be gained by examining the changes that occur in the ovary wall separately from those occurring in the placenta.

Although LNT treatments increased ovary size in both experiments, there were differences between experiments, as indicated previously. Ovaries in Expt. 1 were larger than in Expt. 2 regardless of cultivar or temperature treatments. Differences in ovary size between experiments may in part be explained by harvest frequency (every $3 \mathrm{~d}$ in Expt. 1 versus everyday in Expt. 2) and in part by plant density (13 and 17 plants $/ \mathrm{m}^{2}$ for Expts. 1 and 2, respectively). Previous studies have reported that higher plant densities produce smaller fruits (Cebula, 1995; Cruz-Huerta et al., 2009) and that smaller fruits are correlated with smaller ovaries (Ali and Kelly, 1992).Therefore, it is likely that flowers developed at higher plant densities had smaller ovaries.

The most visible response of bell pepper to low night temperatures during the preanthesis stage is the formation of swollen ovaries, as shown here, and reduction in seed number (Pressman et al., 1998a), both of which result in deformed fruits. Although the present work indicates that non-bell pepper types also respond to LNT by increased ovary swelling, it has not yet been determined whether this translates into a negative effect on final fruit size/shape. Further work is needed to confirm this.

The reduction in seed number in bell pepper observed under LNTs (Pressman et al., 1998a) is caused primarily by lack of successful pollination/fertilization (Kato, 1989; Mercado et al., 1997a, 1997b). Pressman et al. (2006) and Shaked et al. (2004) reported that LNT during the $4 \mathrm{~d}$ before anthesis in bell peppers reduced pollen carbohydrate concentrations, thereby decreasing pollen viability and germinability. This may explain why in commercial operations, even two or three nights of low temperatures cause fruit deformation in those flowers exposed to low temperatures before anthesis. Longer durations of cool night temperatures during flower bud initiation such as occurs in mild winter production areas or greenhouse production in cold areas are likely required to induce swollen ovaries and subsequent fruit malformation; however, the duration of LNT necessary for this response remains unknown.

\section{Literature Cited}

Ali, A.M. and W.C. Kelly. 1992. The effects of interfruit competition on the size of sweetpepper (Capsicum annuиm L.) fruits. Sci. Hort. 52:69-76.

Ali, A.M. and W.C. Kelly. 1993. Effect of preanthesis temperature on the size and shape of sweet-pepper (Capsicum annuиm L.) fruit. Sci. Hort. 54:97-105.

Aloni, B., E. Pressman, and L. Karni. 1999. The effect of fruit load, defoliation and night temperature on the morphology of pepper flowers and on fruit shape. Ann. Bot. (Lond.) 83:529534.

Bhatt, R.M. and N.K. Srinivasa-Rao. 1993. Response of bell pepper (Capsicum annuum L) photosynthesis, growth, and flower and fruit setting to night temperature. Photosynthetica 28:127-132.

Bosland, P.W. 1996. Capsicums: Innovative uses of an ancient crop, p. 479-487. In: Janick, J. (ed.). Progress in new crops. ASHS Press, Arlington, VA.

Cebula, S. 1995. Optimization of plant and shoot spacing in greenhouse production of sweet pepper. Acta Hort. 412:321-329.

Choi, G.-W. and J.M. Gerber. 1992. Studies on flower primordium differentiation of bell pepper (Capsicum annuum L.). HortScience 27:644.

Cruz-Huerta, N., J. Ortiz-Cereceres, F. SanchezDel-Castillo, and M.C. Mendoza-Castillo. 2005. Biomasa e indices fisiológicos en chile morrón cultivado en altas densidades. Rev. Fitotec. Mex. 28:287-293.

Cruz-Huerta, N., F. Sánchez-del-Castillo, J. OrtizCereceres, and M.C. Mendoza-Castillo. 2009. Altas densidades con despunte temprano en rendimiento y período de cosecha en chile pimiento. Agr. Tec. Mex. 35:70-77.

Elitzur, T., H. Nahum, Y. Borovsky, I. Pekker, Y. Eshed, and I. Paran. 2009. Co-ordinated regulation of flowering time, plant architecture and growth by FASCICULATE: The pepper orthologue of SELF PRUNING. J. Expt. Bot. 60:869-880.

Eshbaugh, W.H. 1993. Peppers: History and exploitation of a serendipitous new crop discovery, p. 132-139. In: Janick, J. and J.E. Simon (eds.). New crops. Wiley, New York, NY.

Jovicich, E., D.J. Cantliffe, P.J. Stoffella, and D.Z. Haman. 2007. Bell pepper fruit yield and quality as influenced by solar radiation based irrigation and container media in a passively ventilated greenhouse. HortScience 42:642-652.

Kato, K. 1989. Flowering and fertility of forced green peppers at lower temperatures. J. Jpn. Soc. Hort. Sci. 58:113-121.

Mercado, J.A., M.M. Trigo, M.S. Reid, V. Valpuesta, and M.A. Quesada. 1997a. Effects of low temperature on pepper pollen morphology and fertility: Evidence of cold induced exine alterations. J. Hort. Sci. 72:317-326.

Mercado, J.A., B. Vinegla, and M.A. Quesada. 1997b. Effects of hand-pollination, paclobutrazol treatments, root temperature and genotype on pollen viability and seed fruit content of winter-grown pepper. J. Hort. Sci. 72:893-900.

Munting, A.J. 1974. Development of flower and fruit of Capsicum annuum L. Acta Bot. Neerl. 23: 415-432.

Perin, C., L.S. Hagen, N. Giovinazzo, D. Besombes, C. Dogimont, and M. Pitrat. 2002. Genetic control of fruit shape acts prior to anthesis in melon (Cucumis melo L.). Mol. Genet. Genomics 266:933-941.

Polowick, P.L. and V.K. Sawhney. 1985. Temperature effects on male-fertility and flower and fruit-development in Capsicum annuиm L. Sci. Hort. 25:117-127.

Pressman, E., H. Moshkovitch, K. Rosenfeld, R. Shaked, B. Gamliel, and B. Aloni. 1998a. 
Influence of low night temperatures on sweet pepper flower quality and the effect of repeated pollinations, with viable pollen, on fruit setting. J. Hortic. Sci. Biotechnol. 73:131-136.

Pressman, E., R. Shaked, and N. Firon. 2006. Exposing pepper plants to high day temperatures prevents the adverse low night temperature symptoms. Physiol. Plant. 126:618-626.

Pressman, E., E. Tomer, M. Cohen, K. Rosenfeld, R. Shaked, H. Moshkovitz, and B. Aloni. 1998b. Histological examination of low temperatures or TIBA-induced swelling of pepper ovaries. Plant Growth Regulat. 25:171-175.

SAS Institute Inc. 2008. SAS/STAT ${ }^{\circledR} 9.2$ user's guide. SAS Institute, Cary, NC.

Shaked, R., K. Rosenfeld, and E. Pressman. 2004. The effect of low night temperatures on carbohydrates metabolism in developing pollen grains of pepper in relation to their number and functioning. Sci. Hort. 102:29-36.
USDA Economic Research Service. 2008. Vegetables and melons: Situation and outlook yearbook. In: Lucier, G. and R.L. Dettmann (eds.) 26 Mar. 2009. <http://www.ers.usda.gov/ publications/vgs/2008/05May/VGS2008.pdf>.

Ying, J., E.A. Lee, and M. Tollenaar. 2002. Response of leaf photosynthesis during the grainfilling period of maize to duration of cold exposure, acclimation, and incident PPFD. Crop Sci. 42:1164-1172. 